\title{
DAMPING PERFORMANCE EXPERIMENT AND DAMAGE ANALYSIS OF REPLACEMENT CONNECTION WITH LOW-YIELD-POINT STEEL
}

\author{
Hao-Xiang He ", Li-Can Liao and Shi-Tao Cheng
}

Beijing Key Laboratory of Earthquake Engineering and Structural Retrofit, Beijing University of Technology of Technology, Beijing, China.

*(Corresponding author: E-mail: hhx7856@163.com)

\section{A B S T R A C T}

The performance design for traditional steel rigid connection cannot fulfill the desired seismic requirements. Though beam column connection with weaken beam end can approximately realize the concept about "strong column-weak beam", the local buckling and the distortion buckling in the weaken zone and the total lateral damage maybe occur in rare earthquake and the capacity is not enough. The replacement connection with low-yield-point steel (LYPS) is proposed base on the idea of resilient structure, and its weakened parts in the flange slab and web plate are filled with LYPS. During earthquake, the LYPS primarily yields and fully dissipates energy. The damage of the main parts in the connection is minor and the LYPS can be replaced after the earthquake. According to the insufficiency of the traditional damage models, the damage model based on differential ratio of elastic plastic dissipated energy is proposed. Low cycle loading experimental research is carried out on three kinds of beam-column connections, which involve the classic connection, the beam end weaken connection and the replacement connection. Comprehensive assessments of damping performance are proposed through a variety of performance evaluation parameters. It is approved that the replacement connection has much more excellent bearing capacity, ductility and energy consumption ability. In addition, the proposed energy damage index can represent damage evolution process and damage law.

\section{A R T I C LE H I S T O RY}

$\begin{array}{ll}\text { Received: } & \text { 24 June } 2020 \\ \text { Revised: } & \text { 2 February 2021 } \\ \text { Accepted: } & \text { 6 February 2021 }\end{array}$

\section{K E Y W O R D S}

Low-yield-point steel;

Beam-column connection

Seismic damage model;

Damage index;

Energy dissipation;

Resilient structure;

Damping performance

\section{Introduction}

For seismic design of high-rise steel structures, the design pattern and the energy-dissipating ability of beam-column connection play a significant role, which markedly affect the stability and safety of the whole steel frame. The current common forms of beam-column connection include the column-through type, the type that beam flange is welded with the column and the type that web plate is welded with column or fixed by high-strength bolts.

In the initial study of the steel connection design, the steel flanges is assumed to resist all the bending moments while the web in the beam merely resist all the shear forces. In fact, the bending capacity of the connection occupies up to $80 \%$ of the capacity of the beam, which derogates from the fundamental principle of strong connection and weak beam in earthquake design philosophy [1-3]. During the earthquake occurred in Northridge and Kobe, the phenomenon that the brittle fractures occurred on the rigid connection in many steel structures has urged many researchers to proposed a range of solutions to deal with this adverse situation. Among them, the plastic hinge offset method has become a hot topic in many fields of research, which advocates the shift of stress concentration zone of beams from the vicinity of the connection to the exterior zone [4]. In actual engineering processing mode, the beam end weaken type and the beam end strengthen type are mainly adopted $[5,6]$.

The typical representatives of the beam end weakening connection include the dog-bone connection and the web opening connection [7-10]. However, the beam weaken connection still has the deficiencies as follows. First, when the flange or web is weakened, it is easy to produce large yield deformation at the weakened position. Secondly, due to the weakening of the structure, the bearing capacity and stiffness of the structure are reduced, which is easy to damage and difficult to repair after earthquake. Thirdly, local buckling and global lateral displacement may occur in the weakened zone under strong earthquake, and the safety reserve capacity is insufficient. If subjected to strong earthquake or multiple aftershocks, severe buckling or even fracture may occur in the weakened zone.

On the other hand, the flange or web near the end of the beam will still yield first, although it can dissipate energy, but it is easy to appear irrecoverable damage, which makes the repair of the structure very difficult after the earthquake. Hence, it indicates that there is still something to be improved in the constructional measures and material of the beam-column connection.

In recent studies, the idea about resilient structures has been proposed and developed gradually. The resilient structure has various ways to be achieved in the structural form [11-13]. However, due to the extreme complicacy of construction technology and seismic design, the researches on the replaceability and resilience of steel structure members after serious damage need to be strengthened, and the engineering applications are still less [14-17].

In view of this, a replaceable steel beam-column connection with low-yield- point steel (LYPS) is proposed in order to resolve the existing deficiencies of the beam end weaken connection. For the new connection, the weakened areas in beam are filled with LYPS, which can primarily deform and consume energy fully in earthquake, thus the overall energy dissipation performance is improved. Moreover, the accumulated plastic strain is basically confined to the low-yield-point steel by reasonably setting the weaken size and filling zone, so as to avoid large deformation of beams, therefore, the repair work of the connection after the earthquake can be completed quickly and easily, which represents the idea of structural resilience.

From the perspective of structural seismic evaluation, the structural seismic performance can be represented by means of the damage model or the damage index. Researchers have proposed a variety of types of damage models, including the model based on maximum deformation and relevant improved models [18], the models based on stiffness variation [19], the models based on energy [20], the models based on deformation-energy double criterion and improve the models [21-23], etc. However, most damage models lack explicit mechanisms and sufficient accuracies. Hence, it is significant to develop an accurate, convenient and adaptable dynamic damage model or damage index.

In summary, the traditional connections, the weakened steel connections and the replacement steel connections with LYPS are simulated by finite element method and the experimental specimens are manufactured, and the different types of connections are tested and compared, which proves that the replacement steel connections are more capable of energy dissipation. Besides above study, a seismic damage model based on elastic-plastic energy dissipation different ratio are put forward on the basis of existing research so that we can characterize the damage evolution process and performance level of steel components.

\section{Construction of replacement steel connection}

The main types of weakened connections mainly include flange weaken type and web opening type. The design parameters of weaken part of flange can be calculated according to reference [24]. As shown in Fig. $1, b_{f}$ and $h_{b}$ is the flange width and section height of the beam, respectively. $a$ is the length from the weakening initiation point to the column surface, and it can be taken as $0.50 b_{f}$ $\sim 0.75 b_{f}$. The weakening length $b$ can be taken as $0.65 h_{b} \sim 0.85 h_{b}$, the weakening depth $c$ can be taken as $0.20 b_{f} \sim 0.25 b_{f}$, and the radius of round hole $R$ can be set as $0.25 h_{b} \sim 0.375 h_{b}$

In view of the fact that the beam-end weakening connection may have severe buckling and obvious lateral displacement of the beam under rare earthquakes, a beam-filled connection with LYPS is presented, and the corresponding constructional detail is shown in Fig. 1. The connection is weakened and the part of the original steel of the flange and the web of the steel beam are removed, and then replaced by the weakened part of the LYPS by welding technology to ensure the bearing capacity of the components. During 
the earthquake, the LYPS firstly yield, the elastic-plastic deformation occur and the dynamic energy is dissipated, then the main part of the connection begin to dissipate energy. The LYPS could be replaced after the earthquake. For the sake of making fullest use of the energy consumption capacity of LYPS, it is more advisable that the corresponding weakening parameters should be larger values in the range of traditional weakened connections.

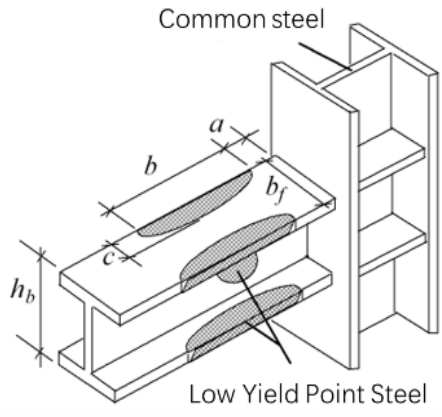

(a) Side looking

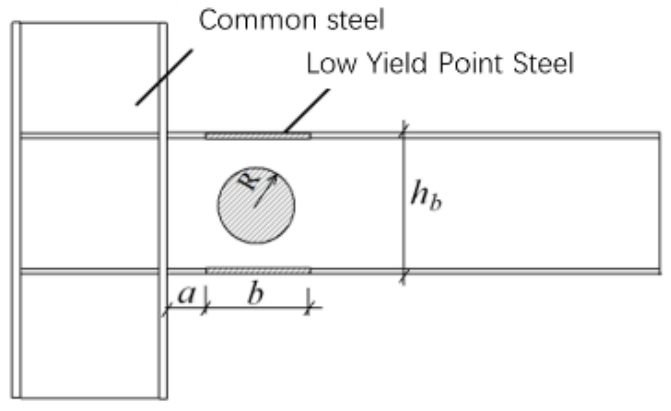

(b) facade

Fig. 1 Beam end weaken and replacement connection

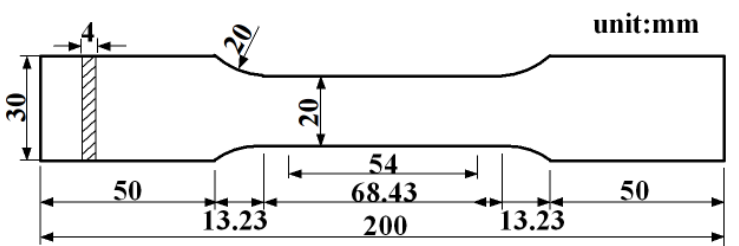

(a) Specimen type and size

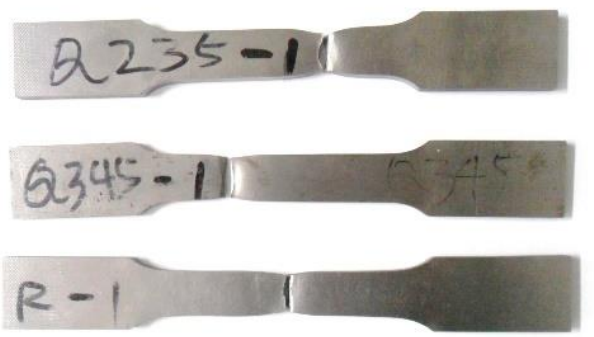

(b) Fracture morphology of specimens

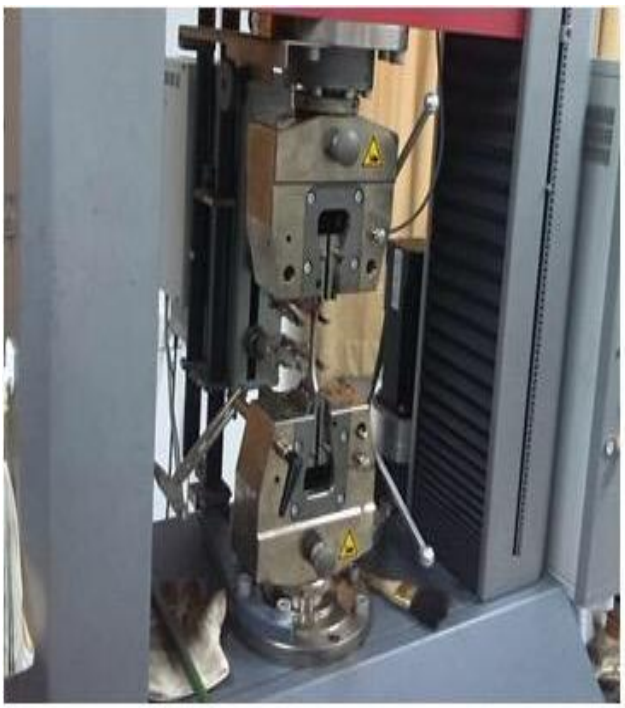

(c) Tensile Testing Device

Fig. 2 Specimen size, tensile test and fracture morphology

\section{Material performance experiment of low-yield-point steel}

There are lots of theoretical studies on damping performance about lowyield-point metal, but the actual low-yield-point materials which meet the requirements of engineering application is very few [25-28]. By comparison, the LY160 steel (the yield strength is about $160.0 \mathrm{Mpa}$ ) is selected as low-yield- point energy dissipation material. To verify the practical material performance of different kinds of steel, three groups of specimens with the same size were fabricated by Q345 steel (the yield strength is about 345.0 Mpa), Q235 steel (the yield strength is about $235.0 \mathrm{Mpa}$ ) and LY160 steel, respectively. The tensile test was carried out in a hydraulic testing machine with the loading stress rate in the elastic stage $16 \mathrm{MPa} / \mathrm{s}$ and the loading strain rate in yield stage $0.0025 / \mathrm{s}$. The average value of each group of material is calculated and taken as the final typical result.

The dimensions of the standard test piece, the tensile test and the fractures of the different material specimens are illustrated in Fig. 2. The corresponding average stress-strain curves for the three types of steel are illustrated in Fig. 3. According to the strain-stress curves obtained from the tensile test, the measured yield strength of Q345 steel, Q235 steel and LY160 steel is 385.2 MPa, 275.3 $\mathrm{MPa}$ and $160.1 \mathrm{MPa}$, respectively, and the measured elongations is $23.2 \%, 27.3 \%$ and $31.3 \%$, respectively. Based on the experimental data, it is evident that LY160 steel has the expected low yield strength and outstanding ductility and toughness, so it could be selected as an energy dissipation material for the replacement steel connections. However, it is still necessary to further verify the damping performance of the replacement steel connections with LYPS through the elastoplastic test of connections.

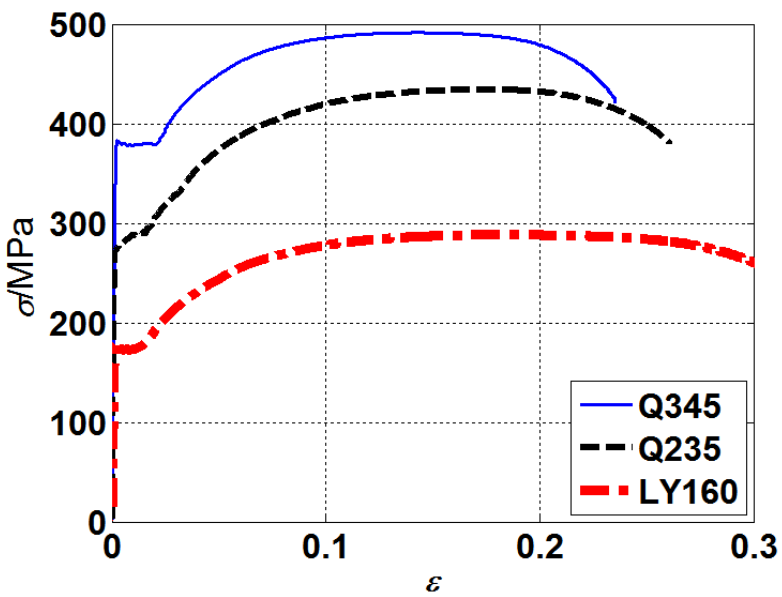

Fig. 3 Constitutive curves of different steels

\section{Design method for replacement connection}

According to the introduction of the beam flange arc weakening connection in reference [29] and the design process of the connection, combined with the concept of the new replaceable connection proposed in this paper, the design steps of the beam-filled connection with LYPS are presented, as shown in Fig. 4.

Assuming $b_{f}, h_{b}, t_{f}$ and $t_{w}$ is the flange width, the section height, the flange thickness and the web thickness of the beam, respectively. $V_{p}$ is the shear force at the plastic hinge, $C_{p r}$ is the coefficient considering the peak bearing capacity, stress-strain strengthening and other conditions, taking as $1.15 . R_{y}$ is the partial coefficient of the material, taking as $1.1, F_{y}$ is the yield strength of metal, $C_{y}$ is a proportional adjustment coefficient, $S_{b}$ is the elastic modulus at the weakening 
point, $V_{g}$ is the beam's yield strength Shear force, $x$ is the distance from plastic hinge to critical section of beam column, $L$ is the distance to column axis, and $d_{c}$ is the section height of column. $Q$ is the uniform load acting on beam.

In the specific design flow, the plastic section modulus of the beam is given

$$
W_{b}=t_{f} b_{f} \frac{h_{b}-t_{f}}{2}+\frac{\left(h_{b}-2 t_{f}\right)^{2}}{8}
$$

The plastic modulus of the weakened part of traditional weaken connection is

$W_{R B S}=t_{f}\left(b_{f}-2 c\right) \frac{h_{b}-t_{f}}{2}+t_{w} \frac{\left(h_{b}-2 t_{f}\right)^{2}}{8}$
Combining Eq. (1) and Eq. (2), it can be deduced that the plastic section modulus of beam-filled beam-column connection with LYPS is

$$
W_{F B S}=t_{f}\left[b_{f}-2(1-\eta) c\right] \frac{h_{b}-t_{f}}{2}+t_{w} \frac{\left[h_{b}-2 t_{f}-2(1-\eta) R\right]^{2}}{8}
$$

where $\eta$ is the coefficient related to the ratio of the elastic modulus of the LYPS to the elastic modulus of the ordinary steel. Since the section modulus of the filling LYPS is between the full section and the weakened section, $\eta$ can be taken according to the following principles: when $\eta$ is 0 , it is the weakened section type; when $\eta$ is 1 , it is the full section type, so the selected $\eta$ value must be between 0 and 1 .

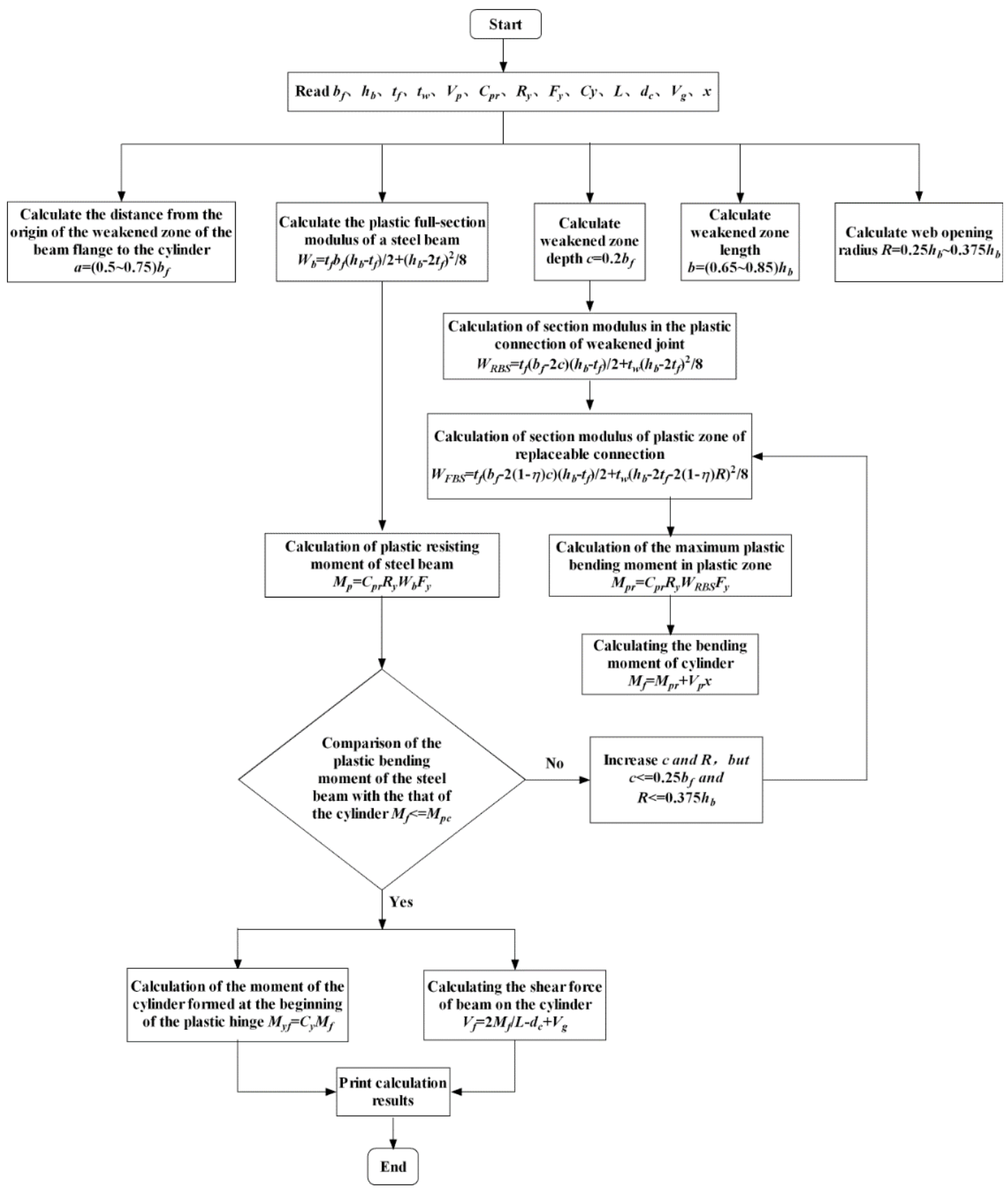

Fig. 4 Design flow chart of replaceable connection

The maximum bending moment in plastic zone is

$M_{p r}=C_{p r} R_{y} W_{F B S} F_{y}$

The bending moment in plastic zone is

$$
M_{p}=C_{p r} R_{y} W_{b} F_{y}
$$

The shear in plastic zone is 
$V_{p}=\frac{2 M_{p r}+P a+Q L^{2} / 2}{a}$

The bending moment of the column is

$M_{f}=M_{p r}+V_{p} x$

The moment of the column when plastic hinge appears is

$$
M_{y f}=\frac{S_{b}}{C_{p r} W_{F B S}} M_{f}
$$

The shear force of beam when the plastic hinge appears is

$$
V_{f}=2 \frac{M_{f}}{L-d_{c}}+V_{g}
$$

\section{Damage model based on elastic-plastic energy dissipation difference ratio}

Besides the design process and the test for the seismic capacity of steel connections, the theoretical analysis and evaluation of the member performance and damage evolution characteristics are also needed. Damage index is an important parameter quantitatively indicate the characteristics of the structural earthquake damage model. The traditional structural damage models include various types, such as strength-based model, displacement-based model, stiffness-based model, period (frequency)-based model, energy-based model, and deformation and energy-based model, etc. It is generally considered that structural displacement and the damage of the cumulative energy interacts each other. Hence, among these models, the Park-Ang damage model, which is a superposition of the maximum displacement and cumulative hysteretic energy, is widely recognized and applied. The damage index $D_{P}$ can be determined as the following method:

$$
D_{P}=\frac{x_{m}}{x_{c u}}+\beta \frac{E_{h}}{F_{y} x_{c u}}
$$

where $x_{c u}$ is the limit deformation with monotonic loading, $F_{y}$ is the yield strength of components, $x_{m}$ and $E_{h}$ is the realistic maximum displacement and cumulative hysteretic dissipation energy, respectively, and $\beta$ is the empirical coefficient, and taken as 0.15 in this study.

However, the disadvantages of Park-Ang model are also obvious, the major deficiencies include: 1) The linear combination mode adopted in this model is lack of sufficient theoretical basis, and it is just a semi-empirical model. The inaccuracy is also manifest in the determination of energy dissipation factors; 2) In general, it is only suitable for static and part dynamic damage analysis of structural components, and the suitability for the time history analysis of total structural damage is worse; 3 ) The limit value do not strictly convergence, and the damage index is not equal to 0 in the elastic stage, and it is usually greater than 1 in the ultimate bearing capacity stage, which seriously affects the damage evaluation precision. 4) It cannot represent the effect of cyclic amplitude variation on the hysteretic dissipation energy during loading, which is called the loading path effect. For the problems above, researchers have revised the original model constantly, but they cannot completely improve all the defects [30-31]. In light of that, the following seismic damage model based on elasticplastic energy dissipation different rate is proposed.

Under an external force with small amplitude, the structure or component generates elastic deformation and corresponding strain energy. At this moment, if the force is withdrawn, the structure will return to the initial displacement without any damage. If the external force is strong, the component or structure will yield and damage, and the strain energy will be dominated by the plasticity energy, and the damage will be more significant as the amplitude of the force increases. If the structure is strengthened to avoid yielding, i.e., the system stay at the ideal elastic state, the damage still does not occur. It is obvious that the form and degree of the damage have a substantial connection with the differences value between the ideal elastic deformation energy of the structure and the actual elastic-plastic deformation energy, and the related differences ratio can be used to represent the damage evolution. Similar to the ideas above, Krajcinovic [32] once proposed the damage theory of concrete and other materials from the perspective of energy loss. That is, the damage variable can be expressed by the ratio of the strain energy in the lossless state to the strain energy and the non-destructive strain energy in the damage state. Now this theory has been applied in material damage assessment and finite element analysis.

For the ideal elastic-plastic SDOF system showed in Fig. 5, the static stiffness of the elastic stage is considered to be $k_{\mathrm{e}}$, the post-yielding stiffness coefficient is $\alpha$, and $F_{y}$ and $u_{y}$ is the yield force and the yield displacement, respectively. When the structure is in the state of elastic-plastic, the force corresponding to the displacement $u_{m}$ is $F_{m}$, the current ductility coefficient is $\mu_{m}=u_{m} / u_{y}$, and the corresponding period is $T_{m}$. Assumed that the equivalent stiffness of the structure in the plastic state can be represented by the secant stiffness $k_{m}$, the damage index based on stiffness can be expressed as

$D_{k}=\frac{k_{e}-k_{m}}{k_{e}}=(1-\alpha)\left(1-\frac{1}{\mu_{m}}\right)=1-\left(\frac{T_{e}}{T_{m}}\right)^{2}$

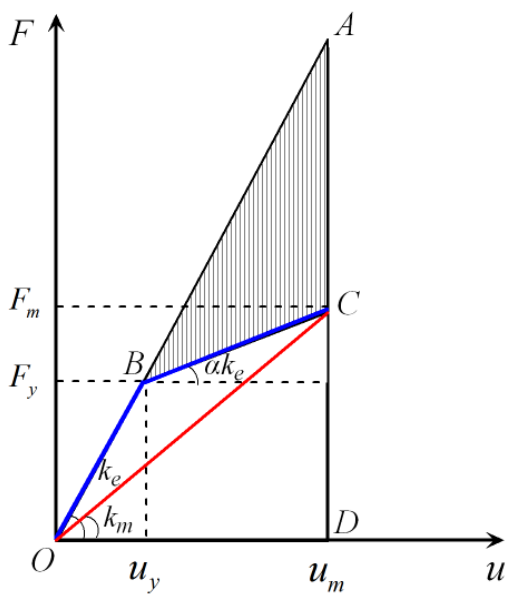

Fig. 5 Energy dissipation of ideal elastic-plastic system

As shown in Fig. 5, the area $S_{O B C D}$ is the actual elastic-plastic deformation energy $E_{F}$ when the structural displacement is $u_{m}$. The area $S_{O A D}$ is the ideal elastic deformation energy $E_{E}$, and the area $S_{A B C}$ is the difference between the two areas, i.e., the difference of elastic-plastic dissipation energy $E_{D}$. According to the elastic-plastic energy dissipation ratio presented by the concept mentioned above, the damage index can be expressed as in this way:

$D_{E}=\frac{E_{E}-E_{F}}{E_{E}}=\frac{S_{A B C}}{S_{O A D}}=(1-\alpha)\left(1-\frac{1}{\mu_{m}}\right)^{2}=\left(1-\frac{1}{\mu_{m}}\right)\left[1-\left(\frac{T_{e}}{T_{m}}\right)^{2}\right]$

It can be seen from the results above that both the damage index based on energy and the damage index based on stiffness can represent the important factors such as resilient force characteristics, maximum elastic-plastic deformation, ductility and period, etc., and the two forms are approximate. The difference between the two indices is that the former shows the square trend of the current ductility, while the latter reveals the linear characteristics of the current ductility, which is in line with their respective theoretical frameworks. In summary, it can be concluded that the damage models on the basis of energy, stiffness, displacement and cycle are closely related with the related representation forms but have different implications. Due to the approximate equivalence, the stiffness-based damage index produces a certain degree of deviation. However, the concept of the energy-based damage index is more rigorous, clear and comprehensive, which is the basis for constructing the most ideal damage model.

As for structural damage under the action of quasi-static forces like lowcycle reciprocating loading, it is generally considered that the cumulative hysteresis energy or system deformation energy can more accurately describe the cumulative damage degree during structural loading. Since the damage model based on elastic-plastic energy dissipation difference ratio involves the restoring force characteristics and displacement response, it can clearly represent the relationships between the deformation energy of the system including the accumulated hysteretic energy dissipation and the ideal elastic deformation energy. Therefore, some improvements on the damage model in the static monotonic force can make it applicable for damage assessment during quasi-static loading.

Let $i$ is the $i^{\text {th }}$ loading step in the loading process, and the structure or component has entered the stage of elastic-plastic under the external force $F(i)$. The base shear force $F_{F}(i)$ and the top displacement $u_{F}(i)$ of the structure can be produced by the experimental technique or nonlinear simulation analysis, so the 
equivalent elastic-plastic deformation energy of the total structure can be expressed as $E_{F}(i)=F_{F}(i) u_{F}(i)$, and the maximum displacement of the top of the elastic-plastic system is $u_{F m a x}$. If the external force $F(i)$ is multiplied by the reduction factort $\gamma$ to ensure that the structure only produces elastic deformation under the action of external force $\gamma F(i)$, and the result of top displacement and its maximum value are $u_{E 0}(i)$ and $u_{E O \max }$, respectively, the base shear force is $F_{E 0}(i)$. Let the amplitude modulation coefficient $\beta=u_{F \max } / u_{E O \max }$. The purpose is to make the maximum elastic displacement of the top of the structure reach $u_{F \max }$. To achieve this goal, $u_{E 0}(i)$ should be mutiplied by $\beta$ times to obtain the amplitude-modulated elastic displacement $u_{E}(i)=\beta u_{E 0}(i)$, and the corresponding amplitude base shear is $F_{E}(i)=\beta F_{E 0}(i)$. Therefore, according to the damage model proposed originally based on the ideal elastic-plastic energy dissipation ratio, the equivalent ideal elastic deformation of the structure under quasi-static force $F(i)$ has the following expression

$E_{E}(i)=F_{E}(i) u_{E}(i)=\beta^{2} F_{E 0}(i) u_{E 0}(i)$

It can be deduced that the structural energy damage index time-history that has entered the elastic-plastic state under the external force $F(t)$ can be expressed

$$
D_{F}(i)=\frac{E_{E}(i)-E_{F}(i)}{E_{E}(i)}=1-\frac{\sum_{i=s}^{n}\left|F_{F i} u_{F i}\right|}{\beta^{2} \sum_{i=s}^{n}\left|F_{E 0 i} u_{E 0 i}\right|}
$$

where $F_{F i}$ and $F_{E i}$ are the elastic-plastic state in the $i^{\text {th }}$ step and the base shear force in the ideal elastic state, respectively, $u_{F i}$ and $u_{E i}$ are the elastic-plastic state in the $i^{\text {th }}$ step and the top displacement in the ideal elastic state, respectively. $s$ is the number of loading steps when the structure transforms from the elastic state into the elastic-plastic state, and $n$ is the entire quantity of steps to be calculated. For structural damage undergoing low-cycle reciprocating loading, the damage index can be calculated separately for each hysteresis loop. If the structure has yielded before the hysteresis loading, $s$ takes 1 . The energy damage index fits the damage analysis of components or structures in different static loading modes, such as monotonic, low cycle reciprocating and pushover analysis, and its numerical value is strictly controlled between 0 and 1 . In the following research, this damage index will be utilized to estimate the damage degree of different connections in the context of reciprocating loading so as to evaluate the seismic performance of various connections more comprehensively.

\section{Simulation of seismic behavior different steel connections}

The seismic performance and damage properties of different types of connections are first verified by finite element method. The traditional connections, the weakened connections and the replacement connections with LYPS are simulated and analyzed by software ANSYS. The FEM models are established and the non-linear analysis under the low cycle reciprocating load is carried out to analyze the energy consumption ability of connections. The beam and column of the connection model are $\mathrm{H}$-shaped steel, the main material is Q345 steel, and the low yield metal is LY160 steel with better ductility. The section size of the column is HW $450 \mathrm{~mm} \times 300 \mathrm{~mm} \times 20 \mathrm{~mm} \times 12 \mathrm{~mm}$; the section size of the beam is $H N 400 \mathrm{~mm} \times 200 \mathrm{~mm} \times 12 \mathrm{~mm} \times 12 \mathrm{~mm}$. The size parameters $a, b, c$ and $R$ of the weakened joint are $125 \mathrm{~mm}, 280 \mathrm{~mm}, 45 \mathrm{~mm}$ and $125 \mathrm{~mm}$, respectively. Both ends of the column of each connection are applied fixed constraints, and the end of the beam is restrained by displacement and cyclic load. The incremental displacement control is adopted until the buckling failure of the member. The equivalent stress diagrams of different types of connections under the limit displacement are shown in Fig. 6-Fig. 8 .

According to the above results, it is found that when the ultimate displacement occur, the maximum stress on the traditional connection is concentrated at the junction of the beam end, and the plastic hinge at the beam end is formed, which causes obvious local buckling. The plastic hinge on the beam-weaken connection moves out to the weakening zone of the beam, which causes serious local buckling and lateral large deformation, and the connection is seriously damaged. The maximum stress of the replacement connection is also concentrated in the connection between the beam end and the column, but the corresponding plastic hinge moves to the zone of LYPS, the energy consumption and the local buckling mainly occur in the LYPS, and the damage of the main material is very small.
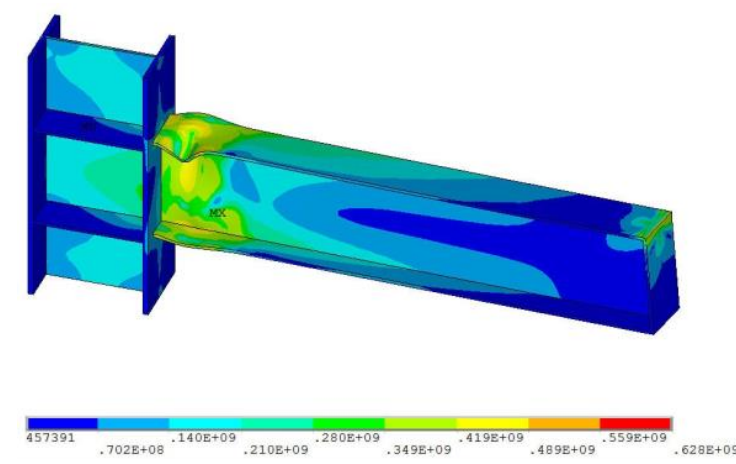

Fig. 6 Stress nephogram of traditional connection
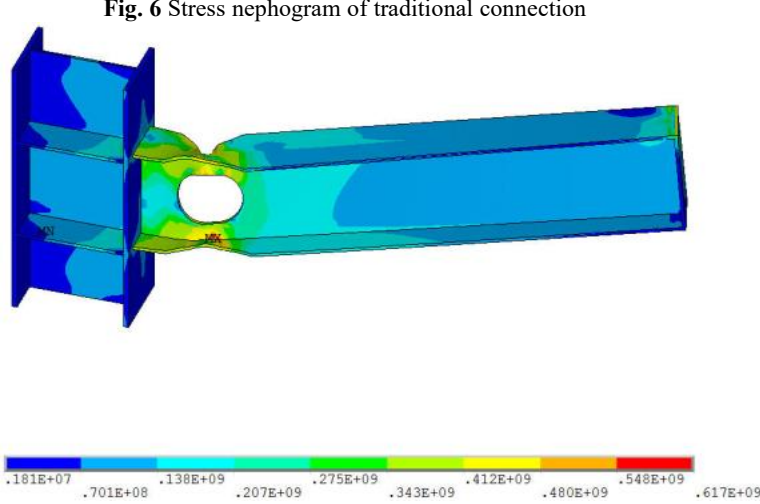

Fig. 7 Stress nephogram of beam-weaken connection
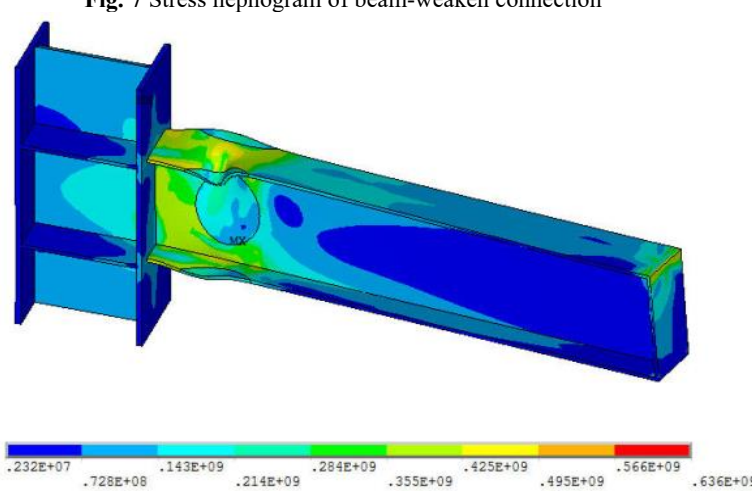

Fig. 8 Stress nephogram of replacement connections with LYPS

The hysteretic loops of different connections are shown in Fig. 9. It can be seen that the hysteresis areas of the traditional connection and the replacement connections are relatively full, while the hysteresis areas of the beam-weaken connection are significantly reduced, and the later bearing capacity drops rapidly, and the energy dissipation capacity is obviously insufficient.

To compare the energy consumption capacity of different connections intuitively, the Park-Ang index is selected to estimate the seismic performance of the connections under low cycle reciprocating load. The Park-Ang index and damage index based on elastic-plastic energy dissipation difference ratio can be calculated according to Eq. (10) and Eq. (14), respectively, the comparative data are shown in Fig. 10 and Fig. 11.

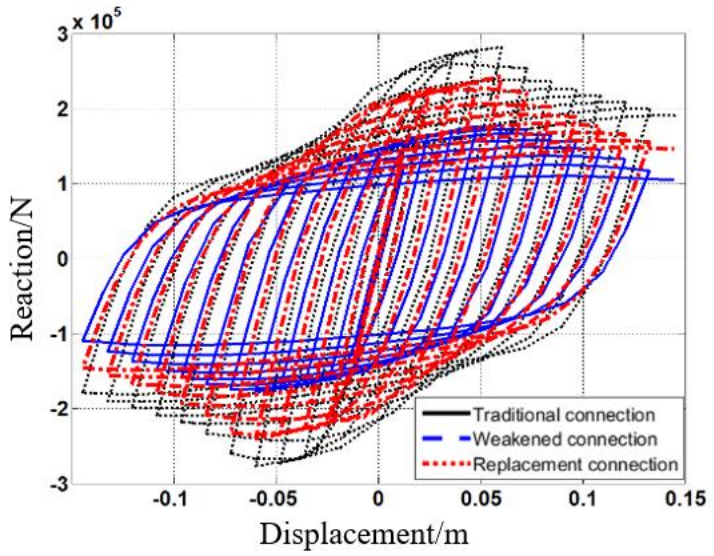

Fig. 9 Hysteresis curves of different connection 


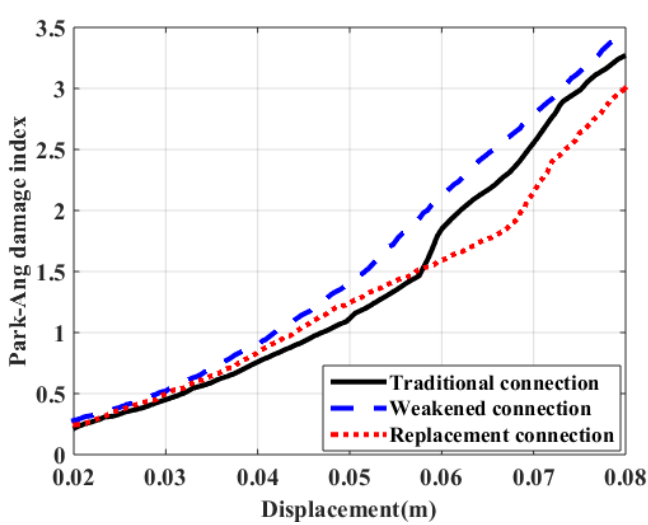

Fig. 10 Park-Ang damage index of different connections

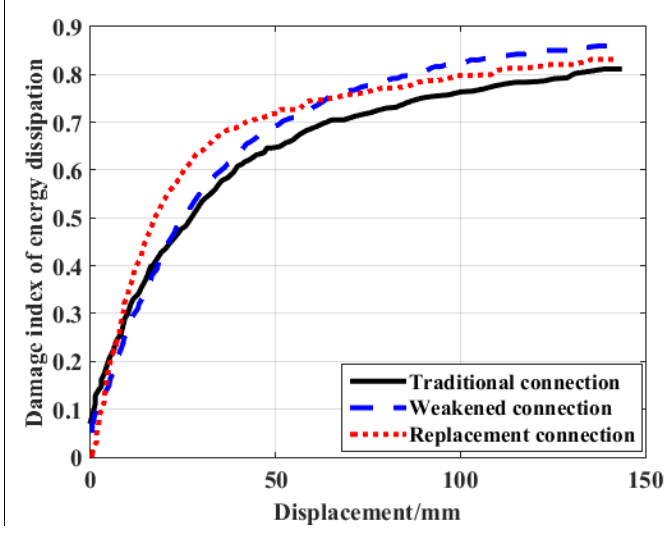

Fig. 11 Damage curves of energy dissipation

In addition, the equivalent viscous damping coefficient (EVDC) $\xi$ can also be used to characterize the damage evolution process of connections, and the relevant formula is given by

$\xi=\frac{E_{D}}{4 \pi E_{S}}$

where $E_{D}$ is the energy dissipated in one integral cyclic loading, equals to the area of the whole hysteresis loop, and $E_{S}$ is the maximum strain energy. The corresponding results are shown in Fig. 12.

It is evident that the EVDC of the traditional connection gradually increases under the low cycle reciprocating load, and it is relatively stable when the connection deforms greatly, but the damage index increases sharply at this time, which indicates that the ductility and the damping capacity of the traditional connection are obviously low, and the damage is serious. In addition, because the common finite element method cannot accurately simulate the brittle failure of the welds, the bearing capacity of the traditional connection is overestimated and the corresponding damage index is underestimated in the simulation. The EVDC of the weakened connection is larger, so it has strong damping capacity and ductility, but the damage is the most serious, local buckling failure occurs early and the carrying capacity is lost. The equivalent hysteretic damping ratio of the replacement connections with LYPS increases rapidly with the accumulation of hysteretic energy consumption. When the displacement is small, it is larger than the traditional connection, but its growth rate slows down with the increase of displacement, and smaller than the traditional connection when the displacement is large. The results show that the replacement connection can fully consume energy since the firstly yield of the LYPS under the reciprocating load, and the integrity of the filled steel connection can still retain due to the better elongation of the LYPS.

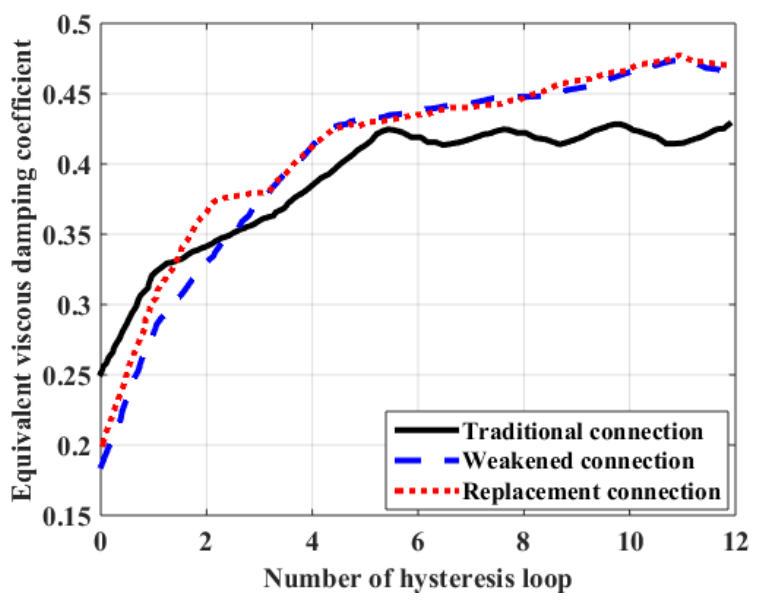

Fig. 12 Equivalent viscous damping coefficient of different connections

In conclusion, the replacement connection has excellent ductility and energy consumption capacity than other connections, and it can impel the plastic hinge move to the weakened zone of the beam, avoiding the emergence of plastic hinge at the connection to cause brittle fracture failure of the structure. Although the dog bone connection can make the plastic hinge move to the weakened zone of the beam, the bearing capacity of the connection declines obviously, which is easy to produce stress concentration and buckling deformation at the weakened part, and the ductility and the damping capacity in later stage is relatively insufficient. Hence, the replacement connection has better seismic performance than the other two connections, but the superior performance needs to be verified by static and dynamic tests.

\section{Test implementation and analysis}

\subsection{Specimen design and size parameters}

To further compare the actual seismic performance of steel structure connections of different structural forms, five full-scale steel structure connection models were designed and fabricated for the low cycle reciprocating static test. The models include one traditional steel structure connection, one weakened steel structure connection and three replacement connections, the specimen code of the connections is TC-1, WC-1, RC-1, RC-2 and RC-3, respectively. All the connections are composed of $\mathrm{H}$-shaped steel. The main structure of the test piece RC-3 is made of Q235 steel while the others are made of Q345 steel. The filling part is made of LY160 steel, the column section size is $250 \mathrm{~mm} \times 250 \mathrm{~mm} \times 14 \mathrm{~mm} \times 14 \mathrm{~mm}$ and the beam section size of the loaded beam $300 \mathrm{~mm} \times 200 \mathrm{~mm} \times 8 \mathrm{~mm} \times 12 \mathrm{~mm}$. Stiffening rib was set $200 \mathrm{~mm}$ away from the end of loading beam to prevent from buckling of loading section. The angle steel parts were arranged in the connection between beam web and column flange and connected by 10.9 grade high strength bolts, the surrounding area is fully welded, and the rest is welded. To compare and analyze the effect of different weakened dimensions on the seismic performance of steel connections, the RC-2 and RC-3 beam flanges and web weakening dimensions of the specimens were all enlarged. The specific material composition and parameters of each test specimen are provided in Fig. 1 and Table 1. In addition, the specific sizes of the connections are shown in Fig. 13.

Table 1

Specimen Types and parameters

\begin{tabular}{cccccc}
\hline Parameter & TC-1 & WC-1 & RC-1 & RC-2 & RC-3 \\
\hline Material & Q345 & Q345 & Q345 & Q345 & Q235 \\
$b / \mathrm{mm}$ & - & 225 & 225 & 280 & 280 \\
$c / \mathrm{mm}$ & - & 40 & 40 & 60 & 60 \\
$a / \mathrm{mm}$ & - & 130 & 130 & 102.5 & 102.5 \\
$R / \mathrm{mm}$ & - & 75 & 75 & 80 & 80 \\
\hline
\end{tabular}



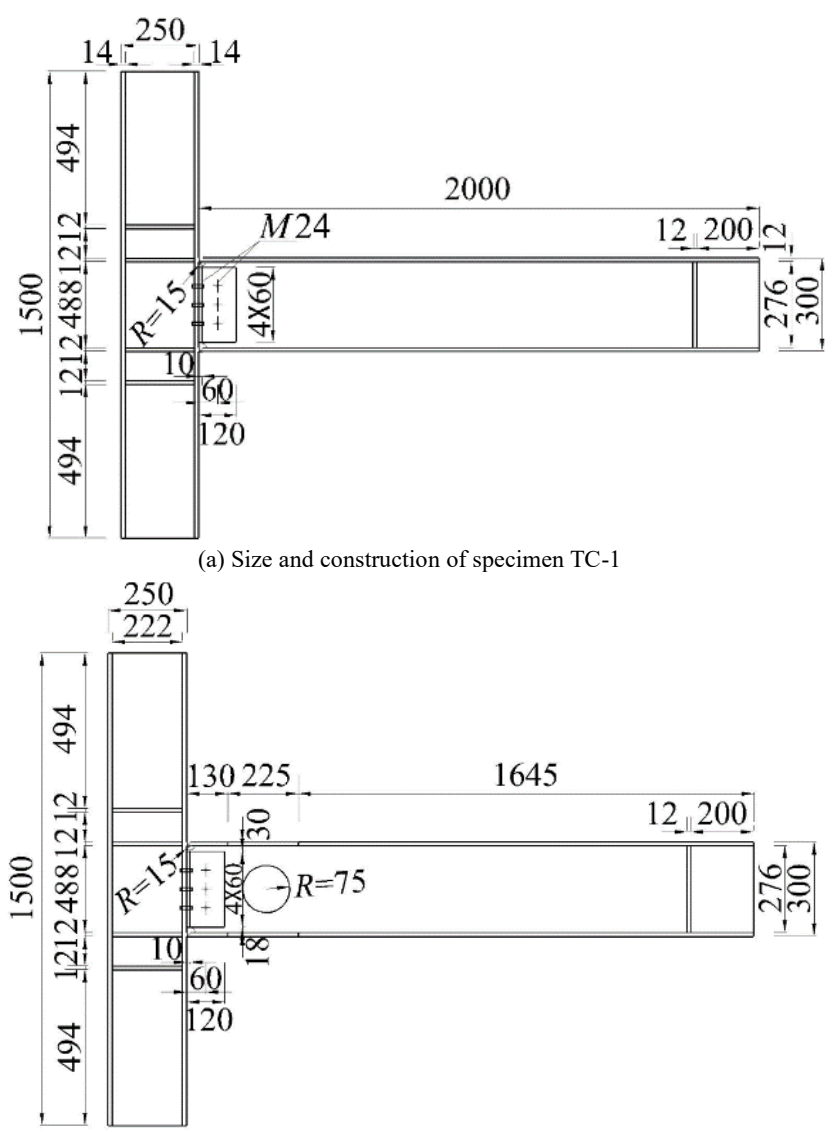

(b) Size and construction of specimen WC-1

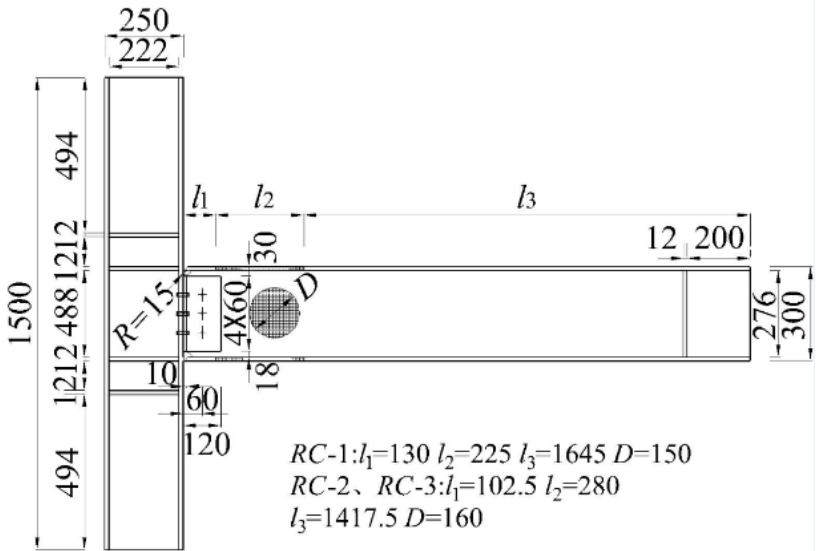

(c) Size and construction of specimens RC-1, RC-2 and RC-3

Fig. 13 Specimen structure diagram (Unit: $\mathrm{mm}$ )

\subsection{Loading scheme}

Not considering the benefits action of column axial force on the shear capacity of the connections, we adopt the beam end loading mode and avoid the axial force of the column. For this reason, the steel column of the connection was placed horizontally and the two ends are anchored on the ground, and the steel beam is placed vertically. The top of the beam was loaded by an electro hydraulic servo jack fixed against one side of the reaction wall. The hydraulic jack can bear $500 \mathrm{kN}$ of the reaction force. The displacement sensor was arranged $200 \mathrm{~mm}$ away from the outer end of the beam. Horizontal push-pull repeated load is controlled by incremental loading. The incremental step of displacement was $12 \mathrm{~mm}$ until the bearing capacity of the connections decreased below $85 \%$ of the peak load or the deformation of the connections is too large to continue loading. The loading scheme is shown in Fig. 14. In the figure, $\Delta$ is the displacement of loading end and $n$ is the total number of cycles of hysteretic energy dissipation loading.

During the test, the data were collected in real time, as the basis for controlling the loading and the result analysis. The data collected included reciprocating loading force and displacement of the bottom and the midpoint on the beam, the strain of the filling flange and the web, etc. The damage developing process and deformation characteristics are observed and recorded during the process of loading. The picture of the loading test site is shown in Fig. 15 .

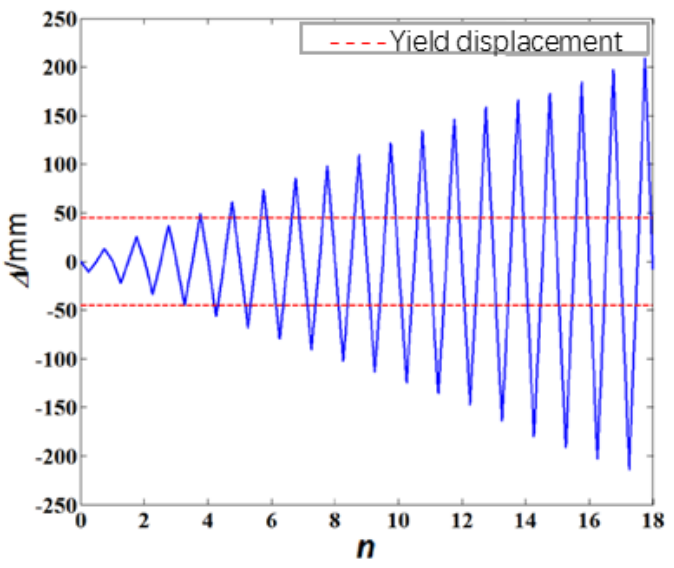

Fig. 14 Displacement loading plan

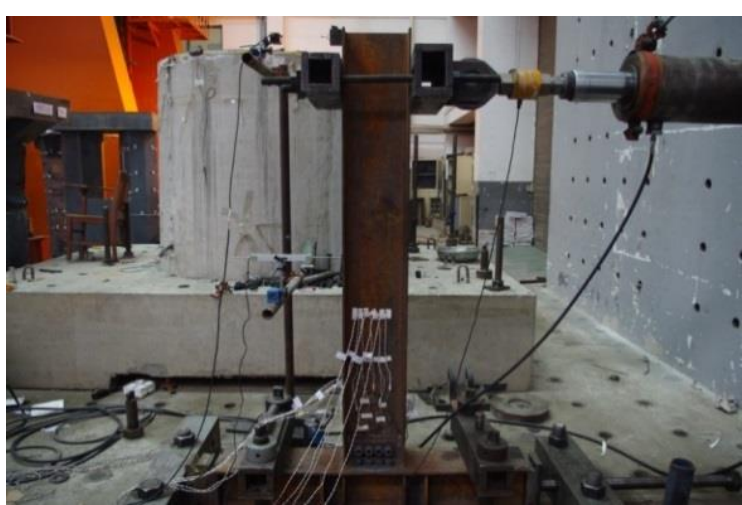

Fig. 15 Test loading diagram

\section{Expeirment phenomenon}

The failure patterns of the connections are shown in Fig. 16. In the experimental process, the specimen TC-1 firstly emerged plastic hinge at the flange of the connection, and then buckled. With the increase of displacement, the web of the beam also entered the yield state, and obvious deformation occurred. In the later stage of loading, the brittle cracks occurred on the weld between the column and the beam flange at the junction, the load dropped sharply and the specimen was destroyed, so that it could not continue to bear the load. 

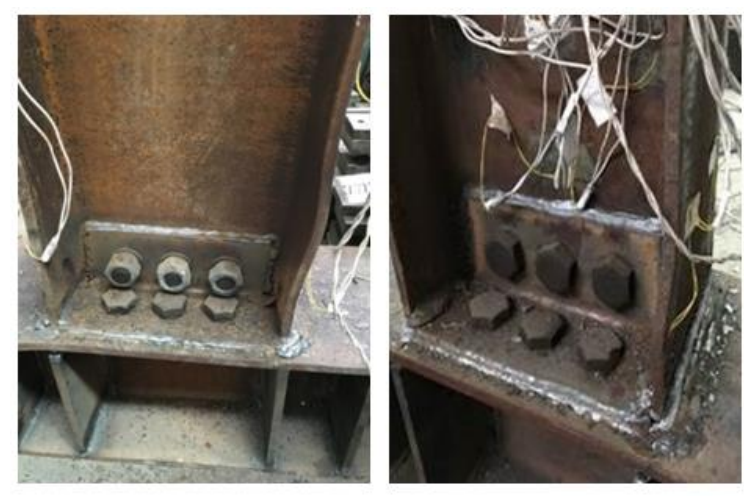

(a) Failure phenomenon of specimen TC-1

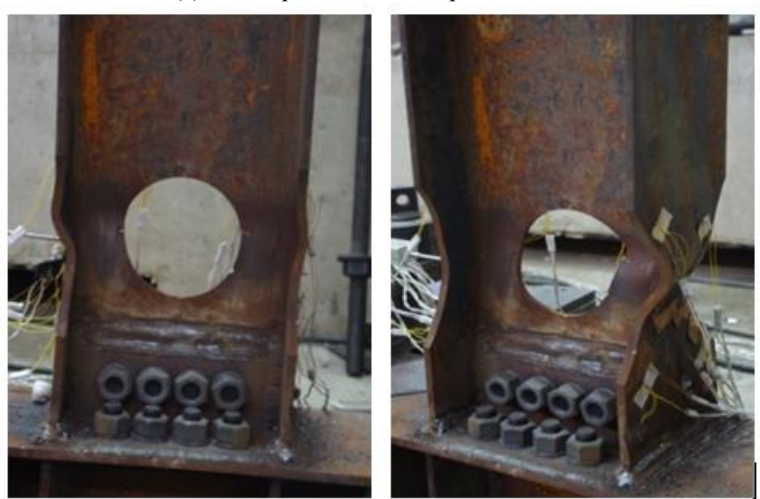

(b) Failure phenomenon of specimen WC-1

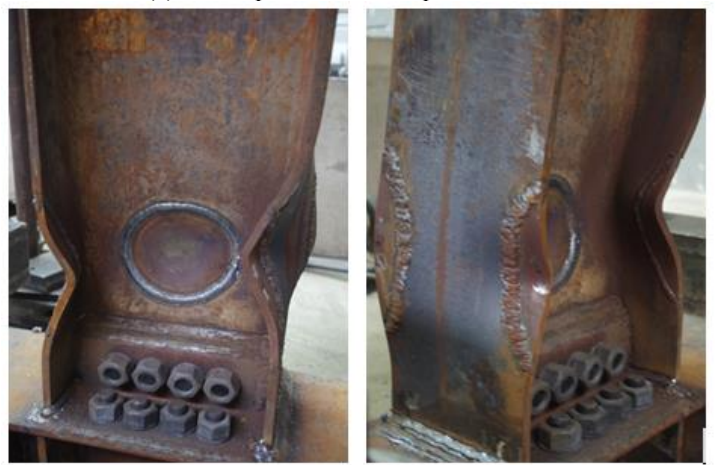

(c) Failure phenomenon of specimen RC-1

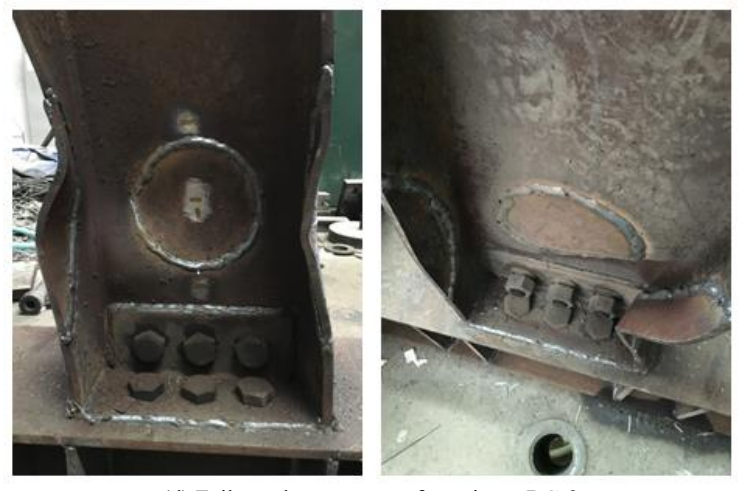

(d) Failure phenomenon of specimen RC-2

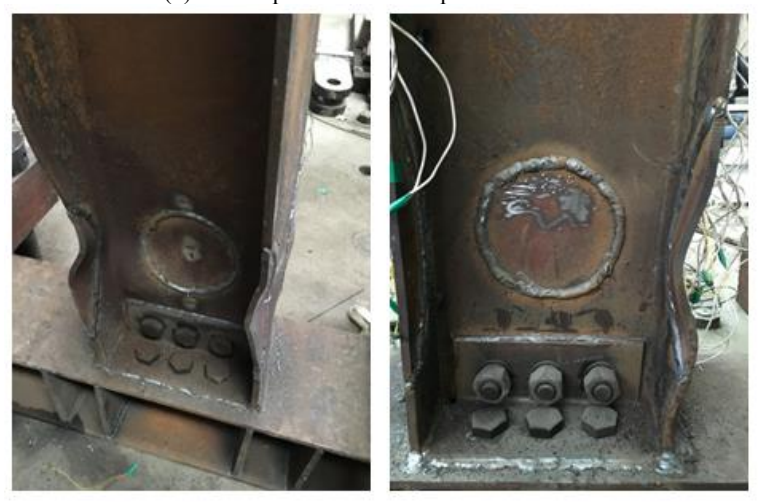

(e) Failure phenomenon of specimen RC-3

Fig. 16 Failure patterns of different specimens
The plastic hinge of specimen WC-1 did not occur at the beam-column connection, but moved outward to the weakened beam. In the initial stage of loading, the flanges of the weakened beam first entered the yield stage, and warping deformation occurred. With the increase of displacement, the local buckling deformation also occurred on the web of the weakened beam. During the subsequent loading, the deformation mainly concentrated on the weakened parts in the flange and web, and the growth was rapid, which caused the specimen to be unable to continue to bear the load. The connection is relatively intact, and the final failure is the beam damaged at the weakening part.

The failure mode of RC-1 is similar to that of WC-1. However, due to the weakened part is filled with the low-yield-point steel LY160, the plastic hinges emerged at the filling part of the beam flange and the warping deformation occurs firstly during the loading process. At this time, the web of the beam does not undergo obvious deformation. Subsequently, the deformation of the LYPS of the beam flange continued to increase, and at the same time, the filling web also entered the yield stage, and significant deformation occurred. At the end of loading, the connection between the main structure and the filling steel could also undergo local deformation.

As the weakened size of the test piece RC-2 is larger, the plastic hinge was generated earlier at the filled steel, the component entered the yield stage, and warpage deformation occurred at the filling beam flange. With the increase of loading displacement, the filling circle of the web began to bulge, and the main part remained intact. At the final stage of loading, the filling part of the specimen gradually failed due to large deformation, while the main part gradually produced obvious deformation.

Due to the main body of RC-3 is made of Q235 steel and the size of weakening is large. The overall load-bearing capacity of the connections is relatively low during loading. After the filling part undergoed large deformation, it loosed its load-bearing capacity. The main part continued to bear the load and the local buckling and the obvious deformation occured on the flange of the beam. The load of the component significantly decreased as the load continued.

The above experimental phenomena indicate that the yield deformation and energy dissipation of RC-1, RC-2 and RC-3 mainly occured in the LYPS, while the material damage of beam-column connection body was relatively small. In the following stage, as the displacement increases, the joint load did not decrease as significantly as WC-1, and it could still bear the load. In addition, though the RC-2 and RC-3 specimens had the effect of plastic hinge moving out due to their large weakening area, the load and energy dissipation capacity have decreased.

\section{Test results and analysis}

To analyze and compare the energy consumption capacity and damage features of different beam-column connections, the experimental data are analyzed. The hysteresis curves, skeleton curve, ductility coefficient, stiffness degradation curve and damage curve of different specimens are calculated and discussed separately.

\subsection{Analysis of hysteresis curve}

The hysteresis data of the connections are analyzed and the comparison results are shown in Fig. 17-Fig. 19. It is obvious that the hysteresis loop of the specimens that filled with LYPS are full and can still has satisfactory ductility and energy consumption capacity in the later stage. Because the specimen WC1 formed plastic hinge at the weakening part at the beginning of loading, the bearing capacity and the area of hysteresis loop decrease significantly, especially in the later period, so the energy dissipation capacity was obviously insufficient. Specimen TC-1 was relatively weak at the weld due to its large overall rigidity, it is the first one that have brittle crackings at the weld joint of beam column connection when the top displacement was loaded to $80 \mathrm{~mm}$, and unable to continue bearing and has worse energy dissipation performance. Due to the large weakening size of $\mathrm{RC}-2$, the plastic hinge was formed at the filling place too early. Compared with RC-1, the load and ductility of RC-2 were decreased. For the specimen RC-3 which used Q235 steel as the main body, the strength of the material was lower than that of Q345, which leads to the decline of the bearing capacity, but the ductility is excellent. 


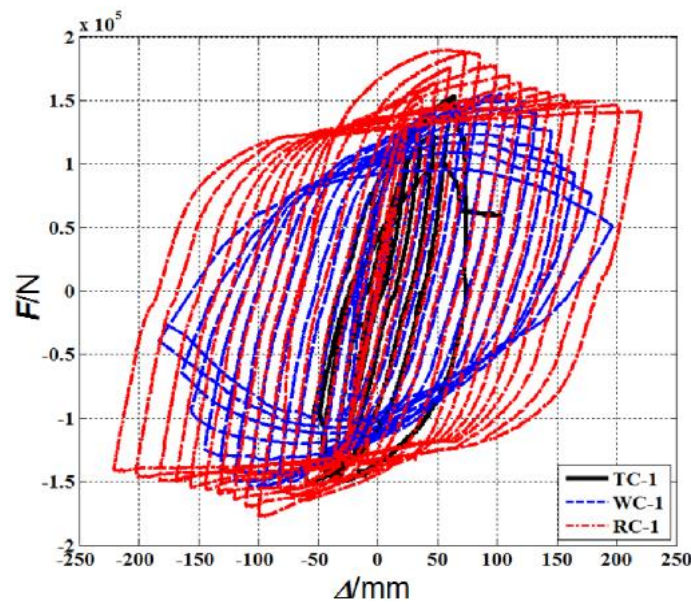

Fig. 17 Hysteresis curves of different connections

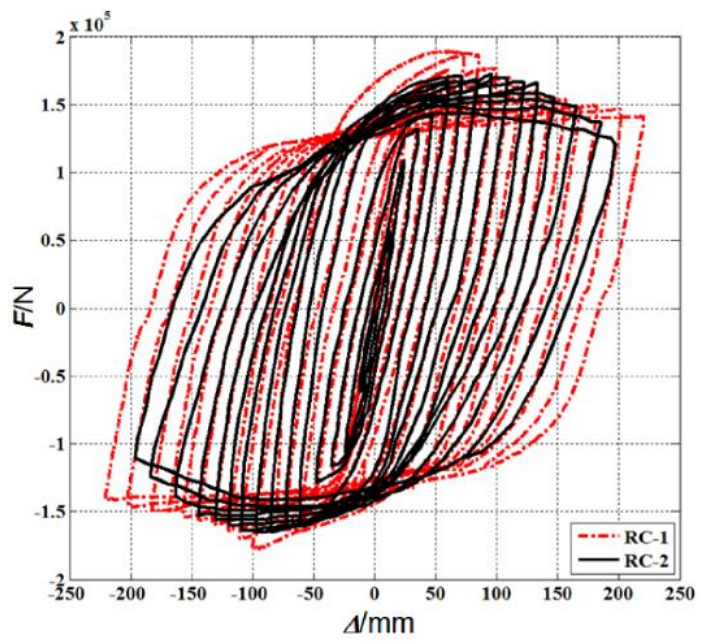

Fig. 18 Hysteresis curves of RC-1 and RC-2

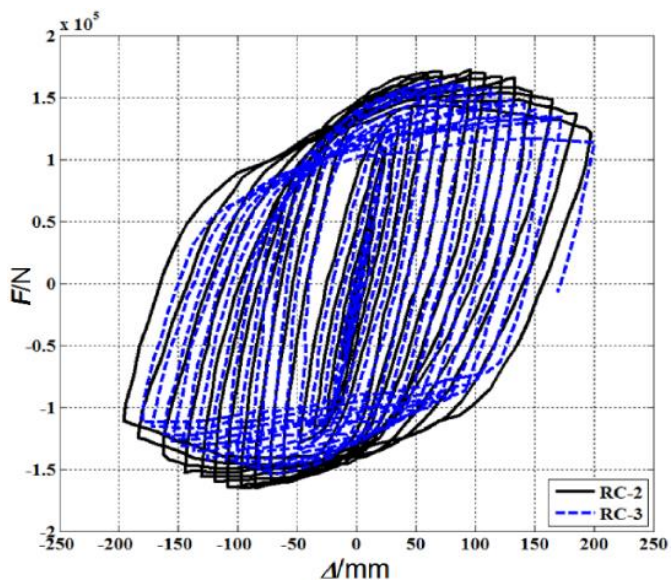

Fig. 19 Hysteresis curves of RC-2 and RC-3

\subsection{Skeleton Curve Analysis}

The skeleton curves of different connections are shown in Fig. 20. It indicates that the initial stiffness of specimen TC-1 is relatively large, and when the loading displacement reaches $47 \mathrm{~mm}$, it enters the yield stage, but when the displacement is $80 \mathrm{~mm}$, the weld cracks at the junction of the beam and the column, and the effective stiffness decreases sharply until the crack developed to complete failure. The load of specimen WC-1 is higher than that of TC-1 under brittle failure. After entering the yield stage, the strength decreases gradually and the stiffness decreases obviously in the later loading phase.

The replacement connections show good ductility and energy consumption capacity at the final stage of loading. Due to the large weakening size of RC-2, the main body of RC-3 is made of Q235 steel, and the load of the weakened joint is reduced after filling. Compared with the weakened specimens, the specimens filled with LYPS can significantly enhance the bearing capacity and the effective stiffness of the connection.

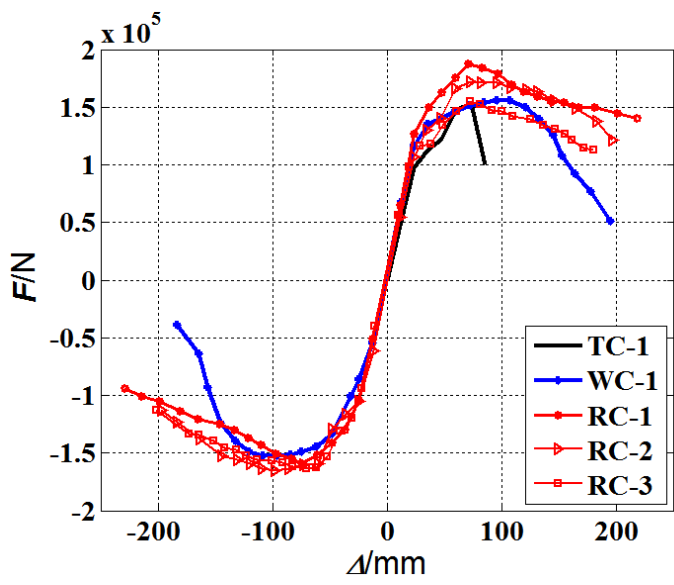

Fig. 20 Skeleton curves of different connections

\subsection{Ductility coefficient}

The displacement ductility coefficient is used to evaluate the ductility ability of connection specimens. It is generally believed that the larger the displacement ductility coefficient is, the better performance of connection specimen is. The displacement ductility factor $\mu$ of the specimen is expressed as

$\mu=\Delta_{u} / \Delta_{j}$

where $\Delta_{u}$ is the ultimate displacement of the specimen and $\Delta_{y}$ is the yield displacement.

The ductility coefficients of different specimens calculated according to Eq.(16) are shown in Table 2. The comparison data show that the failure load of RC-1 specimens increased from $132.22 \mathrm{kN}$ to $159.63 \mathrm{kN}$ on account of the effect of LYPS. The limit displacement increased from $138.45 \mathrm{~mm}$ to $159.63 \mathrm{~mm}$, and the ductility coefficient of RC-1 specimens is $14 \%$ higher than that of weakened connections. It is obvious that $\mathrm{RC}-1$ has good ductility and energy dissipation capacity, since RC-2 and RC-3 have large opening size and Q235 steel is used as the main material for $\mathrm{RC}-3$, the ductility coefficients decreased properly.

Table 2

Bearing capacity and ductility coefficient

\begin{tabular}{cccccc}
\hline Code & TC-1 & WC-1 & RC-1 & RC-2 & RC-3 \\
\hline$P_{y} / \mathrm{kN}$ & 125.77 & 134.44 & 153.29 & 154.97 & 136.50 \\
$\Delta_{\mathrm{y}} / \mathrm{mm}$ & 47.16 & 39.27 & 41.21 & 40.67 & 39.82 \\
$P_{\max } / \mathrm{kN}$ & 153.00 & 154.80 & 187.80 & 172.01 & 160.52 \\
$\Delta_{\max } / \mathrm{mm}$ & 74.00 & 107.17 & 73.64 & 72.81 & 72.47 \\
$P_{u} / \mathrm{kN}$ & 130.05 & 132.22 & 159.63 & 146.21 & 131.34 \\
$\Delta_{u} / \mathrm{mm}$ & 82.40 & 138.45 & 166.13 & 161.56 & 144.53 \\
$M$ & 1.75 & 3.52 & 4.03 & 3.97 & 3.63 \\
\hline
\end{tabular}

Note: $P_{y}$ is yield load, $\Delta_{\mathrm{y}}$ is yield displacement, $P_{\max }$ is peak load, $\Delta_{\max }$ is peak displacement, $P_{u}$ is failure load, $\Delta_{u}$ is failure displacement, $\mu$ is ductility coefficient.

\subsection{Stiffness degradation analysis}

Stiffness degradation is an important performance indicator for structural seismic performance evaluation. The stiffness referred in this study is the equivalent stiffness of the beam-column connection, that is, the slope of the line connecting the origin of the hysteresis curve with the peak load of a certain cycle (point on the skeleton curve). With the displacement continuously increase, the equivalent stiffness will continuously degrade. This phenomenon is called equivalent stiffness degradation. According to the hysteresis curve of the connection, the value of the equivalent stiffness to the maximum stiffness can be calculated, i.e., the equivalent stiffness degradation coefficient $K$ can be obtianed. The stiffness degradation curves are shown in Fig. 21.

It can be seen that the results of the forward and reverse loading of the specimens is not completely symmetrical, mainly due to the accumulated damage of the specimens in the process of reciprocating loading. With the 
increasement of loading displacement, the stiffness degradation of specimen TC-1 is the most significant, and the degradation rate is higher than that of the other two types of specimen in the later loading phase. The stiffness degradation coefficient of the weakened specimen WC-1 decreases significantly after buckling deformation occurs at the beam flange. When the deformation of the beam end reaches $100 \mathrm{~mm}-200 \mathrm{~mm}$, serious deformation occurs at the web openings, and the stiffness degradation coefficient will decrease significantly, and finally only about $6 \%$ of the initial stiffness. By contrast, the stiffness degradation of filled specimens is relatively slow, and the equivalent stiffness degradation coefficient of RC-1 develops slowest in the later stage, which has good ductility and energy dissipation capacity.

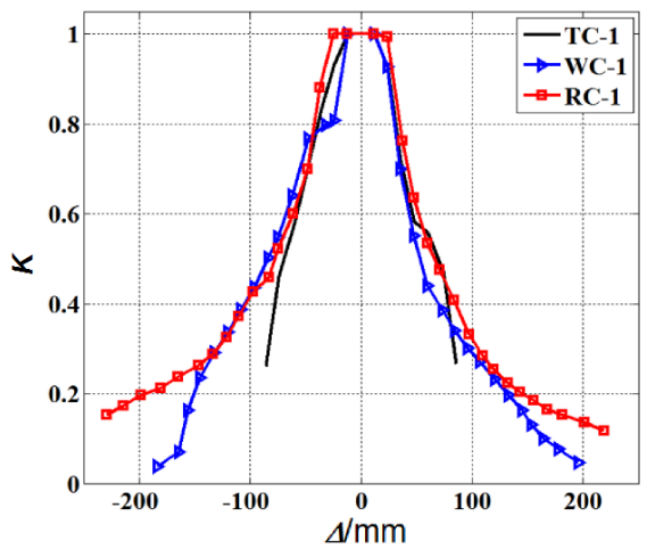

(a) Degradation comparison of traditional, weakened and filled nodes

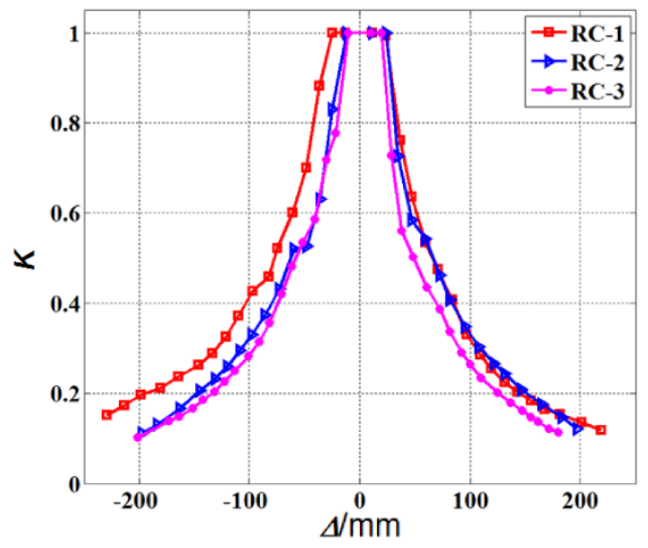

(b) Degradation comparison of three kinds of connections with different filling sizes

Fig. 21 Equivalent stiffness degradation curves

\subsection{Damage Analysis}

Park-Ang damage curve $D_{P}$ of three different components is calculated according to Eq. (11), as showed in Fig. 22. It is found that the stress concentration occur at the joint of beam and column for TC-1, and the damage developed fastest and the damage index is larger. When the beam end was loaded to $80 \mathrm{~mm}$, the damage rised sharply and ultimately was destroyed damages due to brittle cracking in the welding seams of the beam-column joint. For specimen WC-1, the deformation speed of the weakened areas in the flange and web were accelerated when the plastic hinge occured at the end of the beam. Subsequently, with the increase of the deformation at the weakening area, the loading damage rate increases continuously and the specimen ultimately destroyed. The damage evolutions of RC-1, RC-2 and RC-3 were similar, and the damage rate kept rising steadily in the middle and late loading period. Due to the main structure materials of RC-3 is Q235 steel and the size of weakening is large, the damage occured rapidly, but it is generally lower than that of TC-1 and WC-1. Hence, it is obvious that the LYPS at the filling zones has good damping effect and retarded the damage development speed. In addition, when Park-Ang damage index reaches 1 , all connections have not reached complete damage state, and the damage index of WC-1 and filled connections has reached 1.4 when it completely destroyed. It can be considered that using the Park-Ang damage index to evaluate connection damage usually overestimates the damage degree and lacks an accurate threshold range.

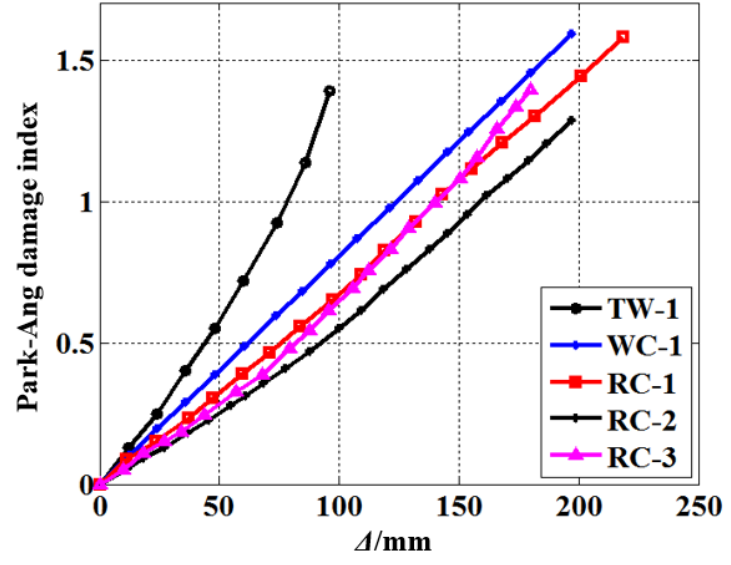

Fig. 22 Damage curves of Park-Ang model

The equivalent viscous damping coefficient $\xi$ is an important energy dissipation index in structural seismic performance analysis. The equivalent viscous damping coefficient of three different connections is calculated according to Eq. (15), as showed in Fig. 23. The energy consumption capacity of traditional connections is the worst, and the maximum of $\xi$ is 0.3 . The equivalent viscous damping coefficients of weakened connections and replacement connections were enhanced. In the early stage of loading, the weakened area in flange and web of the weakened connection yielded and deformed greatly. The energy dissipation of the weakened connection is stronger than that of the replacement connection. However, the deformation at the later stage of loading is too large to continue bearing, so the damping capacity was reduced. The LYPS in the replacement connections firstly yielded in the early stage of loading, but the deformation was small. In the late stage of loading, with the deformation incensement of LYPS, the energy consumption capacity of filled connections is better than that of weakened connections, and increased with the enlargement of displacement. It is obvious that replacement connections had better energy dissipation capacity.

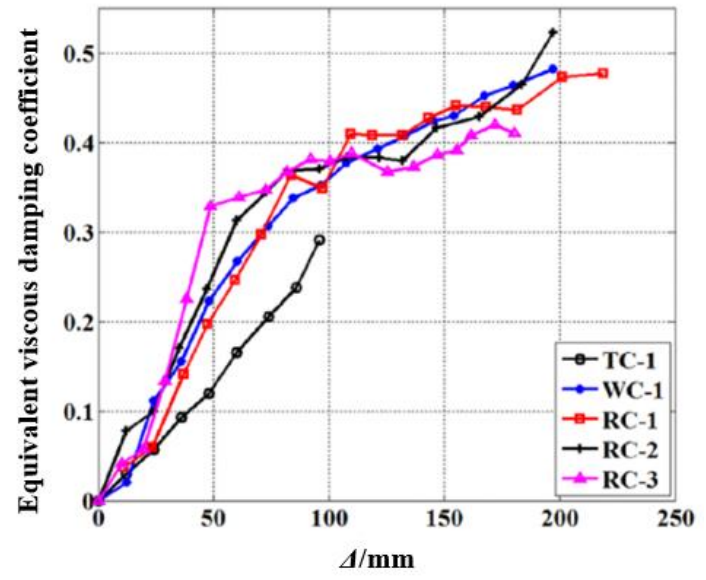

Fig. 23 Curves of equivalent viscous damping coefficien

According to Eq (12), the damage values $D_{E}$ of different specimens are calculated based on elastic-plastic energy dissipation ratio to evaluate the damage evolution process and damping capacity. The specific damage curves are compared in Fig. 24.

It can be found that the damage index of the specimen is strictly controlled between 0 and 1 . Although the damage of TC-1 is less than that of the other two connections in the early stage, when it is loaded to $70 \mathrm{~mm}$, the cracks occured in the welds at the junction of the members. Continuous loading leaded to complete cracking of the welding seams, and the component could not continue to bear the load and destroied, and the damage developed rapidly. The damage of replacement connections was always less than that of WC-1. The damage of weakened specimens and filled connections was increasing at the beginning of loading. When the displacement reached about $80 \mathrm{~mm}$, the damage rate begined to decrease, which is related to the failure of the connections. The maximum of the damage index reached about 0.9 , indicating that the test speciman had been completely destroyed at this time, and it also proves that the damage model can more realistically reveal the damage evolution law during the actual loading process. The low-yield-point steel in the replacement connections provides good 
energy absorbing and damping effect, and the damage of the speciman is effectively mitigated.
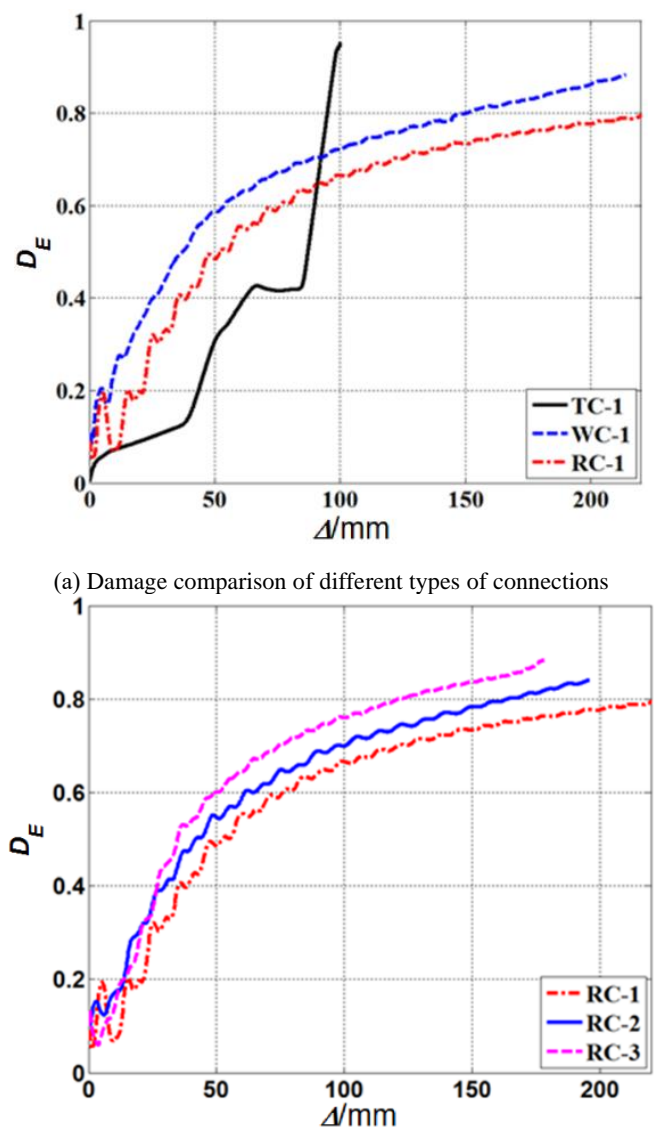

(b) Damage comparison of different replacement connections

Fig. 24 Comparison of damage curves of elastic-plastic energy dissipation ratio difference of specimens

It can be seen from the damage curves that the three damage evaluation models can represent the damage development law of the connection to a certain extent. The Park-Ang index exceeds 1 prematurely, and the damage develops rapidly with the increase of displacement. The equivalent hysteretic damping ratio and the damage curve based on the elastic-plastic energy dissipation ratio have the characteristics of gradual smoothness, and the value of the latter is strictly between $0 \sim 1$. The reason is that the denominator of energy damage term in Park-Ang model is a constant, and the numerator, which represents the cumulative hysteresis energy, will increase with the increase of hysteresis loops. Therefore, the value of energy item of this model actually represents the growth trend of hysteretic energy consumption, but does not fully indicate the damage evolution characteristics. In addition, the corresponding maximum is likely to exceed the upper limit of the damage threshold of 1 because the value is not the relative change rate of energy. On the contrary, the energy damage index can characterize the evolution process of damage according to the change rate of energy, which solves the above problems well, and its specific value and change rule are more accurate and intensive.

\section{Conclusions}

In view of the lack of seismic capacity and serious damage of the traditional steel connections subjected to earthquake, the research on the beam end weakened or beam end strengthened connections has attracted much attention. However, irreparable damage and lateral displacement will still occur in the improved connections. For the sake of improving the ductility and the bearing capacity of weakened connections and reduce the damag degree, a new pattern of replacement connection is presented in this study. For this new beam-column connection, the low-yield-point steel (LYPS) is selected to fill the weakened areas in the flange and web. In the earthquake, the LYPS firstly yields and dissipates enough energy, which can reduce the damage of main body.

The material test results show that the LYPS is superior to the ordinary steel in ductility and toughness, and it is indeed suitable for energy dissipation. This provides enough material guarantee for the seismic performance of new connection.
The seismic performance evaluation of steel structure connections should be carried out based on accuate damage index and damage model. In view of the shortcomings of the current earthquake damage models, a seismic damage model based on elastic-plastic energy dissipation different rate is presented. The mechanism of new damage index is clear and the threshold value is strict, which provides a good evaluation standard for damage evaluation.

Based on the experimental study and simulaton analysis of the traditional connections, weakened connections and replacement connections, the mechanical characteristics, failure patterns and seismic performance of steel connection members are obtained. The test results indicate that the mechanical behavior of the replacement connection with LYPS is different from that of traditional connections and weakened connections. Under the action of earthquake, the LYPS firstly yields and sufficiently consumes energy, thus the replacement connection has superior ductility, strength and energy consumption capacity. By reasonably design for the filling zone, the accumulative plastic deformation can be confined in the zone of the LYPS, and the serious damage and the large deformation in the beam is prevented. After the earthquake, the strengthening and maintenance of the connection can be completed quickly and simply, which can reflect and realize the concept of resilient structures.

The structure damage model based on elastic-plastic energy dissipation different rate can accurately represent the damage evolution law of the structure, and can be applied to different loading modes. At the same time, it can be strictly controlled between 0 and 1 . In additon, based on the design theory of weakened connetion, the seismic design process and formula of new connetion are put forward.

Due to the need for improvement in the structural design, parameter analysis and actual replacement process and method of the replacement conneciton, the relevant research, especially fine finite element modeling, simulation and dynamic analysis, also needs to be carried out in the future.

\section{Acknowledgments}

The financial support of National Natural Science Foundation of China Grant No.51878017 and No. 51678008 is greatly appreciated.

\section{Reference}

[1] Tsavdaridis. K. D, Pilbin C, Lau C. K. FE parametric study of RWS/WUF-B momen connections with elliptically-based beam web openings under monotonic and cyclic loading. Int J Steel Struct 2017,Vol.17,No.2,pp. 677-694.

[2] Akrami. V, Erfani. S . Review and Assessment of Design Methodologies for Perforated Steel Beams, J. Struct. Eng 2016,Vol.142,No.2.

[3] Saleh. A, Mirghaderi. SR, Zahrai. SM, Seyed Mehdi Zahrai, Cyclic testing of tubular web RBS connections in deep beams, Journal of Constructional Steel Research 2016,Vol.117,pp. 214-226.

[4] Ardavan A, Hajirasouliha I, Jazany. RA, Izadinia. M, Optimum drilled flange momen resisting connections for seismic regions, Journal of Constructional Steel Research 2015,Vol.112,pp. 325-338.

[5] Mehmet Alpaslan Köroğlu1, Ali Köken, Yunus Dere, Use of different shaped steel slit dampers in beam to column connections of steel frames under cycling loading, Advanced Steel Construction 2018,Vol.14,No.2,pp. 251-273

[6] Ali Koken, E. Tuba Hatipoglu, Investigation of the behavior of weakened and strengthened steel column-beam connections under seismic effects, Advanced Steel Construction 2014 Vol.10,No.0,pp. 1-13.

[7] Mohammad Davarpanah, Hamid Ronagh, Parham Memarzadeh, Farhad Behnamfar. "Cyclic behaviour of elliptical-shaped reduced web section connection", Structures, 2020,Vol.24,pp.955-973

[8] Momenzadeh S , Kazemi M T , Asl M H . Seismic performance of reduced web section moment connections. International journal of steel structures 2017,Vol.7,No.2,pp. 413-425.

[9] Saeed Erfani, Vahid Akrami, "A Nonlinear Macro model for Numerical Simulation of Perforated Steel Beams," International Journal of Steel Structures 2019,Vol.9,No.5,pp. 1605 1623.

[10] Saeed Erfani, Vahid Akrami. "Increasing Seismic Energy Dissipation of Steel Moment Frames Using Reduced Web Section (RWS) Connection", Journal of Earthquake Engineering, 2016,pp.1090-1112

[11] Garoosi AllahReza Moradi, TahamouliRoudsari Mehrzad, Hashemi Behrokh Hosseini, "Experimental evaluation of rigid connection with reduced section and replaceable fuse," Structures 2018,Vol.16,pp. 390-404

[12] Xiaodong Ji, Yandong Wang, Qifeng Ma, "Cyclic Behavior of Replaceable Steel Coupling Beams," Journal of Structural Engineering 2017,Vol.143,No.2.

[13] LU Xilin, CHEN Cong, "Research progress in structural systems with replaceable members," Earthquake Engineering and Engineering Dynamics 2014,Vol.34,No.1,pp. 27-36.

[14] Myoungsu Shin, Seung-Pil Kim, Arne Halterman, Mark Aschheim, "Seismic toughness and failure mechanisms of reduced web-section beams: Phase 1 tests," Engineering Structures 2017,Vol.141,pp. 198-216.

[15] Richards, Paul W. , and S. S. Oh . "Cyclic Behavior of Replaceable Shear Fuse Connection for Steel Moment Frames." Journal of Structural Engineering 2019, Vol.145. No.12.

[16]Ali K, Mehmet A K. Experimental Study on Beam-to-Column Connections of Steel Frame Structures with Steel Slit Dampers. Journal of Performance of Constructed Facilities, ASCE 2015,Vol.29,No.2,pp. 40-66.

[17] Ai-Lin Zhang, Guang-Hao Shangguan, Yan-Xia Zhang . "Experimental study of resilient prefabricated steel frame with All-bolted Beam-to-Column connections." Advanced Steel Construction 2020, Vol. 16, No. 3, pp. 255-271.

[18] Powell G H, Allahabadi R. Seismic damage prediction by deterministic method: concept and procedures. Earthquake Engineering and Structural Dynamics 1988,pp. 719-734. 
[19] Lei Xu1,Yuxin Liu. Inelastic analysis of steel frames accounting for stiffness degradations. Advanced Steel Construction 2006, Vol. 2, No. 4, pp. 355-373.

[20] Kratzig W B, Meyer I F, Meskouris K. Damage evolutionin reinforced concrete member under cyclic loading $[\mathrm{C}] /$ /Proceedings of 5th International Conference on Structural Safety and Reliability. San Francisco: American Society of Civil Engineers 1989, pp. 795-802.

[21] Huang, W, Zou M, Qian, J, Zhou, Z. Consistent damage model and performance-based assessment of structural members of different materials. Soil Dyn Earthq Eng 2018,Vol.109,pp. 266-272.

[22] HE Haoxiang, CONG Maolin, LV Yongwei. Earthquake Damage Assessment for RC Structures Based on Fuzzy Sets. Mathematical Problems in Engineering 2013,Vol.22.

[23] Wei Huang, Jiang Qian \& Zhi Zhou, "Seismic Damage Assessment of Steel Reinforced Concrete Members by a Modified Park-Ang Model," Journal of Asian Architecture and Building Engineering 2016,Vol.15,No.3,pp. 605-611.

[24] YU Yousheng, WANG Yan. Experimental Study On The Mechanical Property of Reduced Beam Section Connections of Steel Frames. Engineering Mechanics 2009,Vol.26,No.2,pp. 168-175.

[25] Huanjun Jiang, Shurong Li, Liusheng He, "Experimental Study on a New Damper Using Combinations of Viscoelastic Material and Low-Yield-Point Steel Plates," Frontiers in
Materials 2019, Vol.6.

[26] Zhang C , Zhang Z, Shi J . Development of high deformation capacity low yield strength stee shear panel damper. Journal of Constructional Steel Research 2012,Vol.75,pp. 116-130.

[27] Wang M , Fahnestock L A, Qian F. Experimental cyclic behavior and constitutive modeling of low-yield-point steels. Construction and Building Materials 2017,Vol.131,pp. 696-712.

[28] Meng Wang, Xiaogang Ke . "Seismic design of widening flange connection with fuses based on energy dissipation." Journal of Constructional Steel Research 2020, Vol. 170.

[29] FEMA.Recommended Seismic Design Criteria For New Steel Moment-Frame Building,FEMA-350.Washington D.C.:Federal Emergency Management Agency,2000

[30] Huanjun Jiang, Bo Fu, Xilin Lu, Linzhi Chen, "Seismic Damage Assessment of RC Members by a Modified Park-Ang Model," Advances in Structural Engineering 2015,Vol.18,No.3,pp 353-364.

[31] Huanjun Jiang, Bo Fu, Xilin Lu, Linzhi Chen, "Constant-Damage Yield Strength Spectra for RC Structures Using Modified Park-Ang Damage Model," Advances in Structural Engineering 2015,Vol.18,No.6,pp. 837-851.

[32] Krajcinovic D, Lemaitre J. Continuum damage mechanics theory and applications [M]. New York: Springer Verilag 1987. 233-294. 